\title{
Zizi Papacharissi (2010, Malden, MA: Polity Press), A Private Sphere: Democracy in a Digital Age [Uma esfera privada: democracia na Era Digital]
}

\author{
Sónia Pedro Sebastião \\ ssebastiao@iscsp.utl.pt \\ ISCSP (UTL) - CAPP
}

O livro A Private Sphere: Democracy in a Digital Age de Zizi Papacharissi é sobre novos hábitos cívicos que emergem da relação entre a democracia e a tecnologia, procurando compreender a forma como a tecnologia transforma as relações pessoais através de processos que conduzem a novos hábitos comunicativos, ou seja, visa evidenciar como as pessoas se "conectam" nas democracias contemporâneas. A autora questiona fundamentalmente dois conceitos: cidadania e esfera pública. Para tal, divide a sua obra em seis capítulos que abordam os conceitos de democracias contemporâneas, envolvimento cívico e media; público e privado; convergência dos media, das audiências e dos públicos; cidadania; esfera pública e esfera privada.

De acordo com a autora vivemos perante uma multidão de cidadãos "digitally enabled and digitally extended" (p. 2), numa democracia representativa marcada pelo cinismo, pela apatia e por eleitorados "desconectados". Além disso, a esfera pública foi definida como o locus referencial dentro do qual a deliberação cívica e a participação se situam, numa democracia representativa (p. 12), ainda que, nesta esfera, o cidadão se sinta impotente, sem controlo e sem confiança nos atores e nas instituições.

Por isso, Papacharissi questiona se não será o conceito de democracia que se encontra desfasado das práticas cívicas atuais, uma vez que nunca houve uma omnipresença da tecnologia na vida dos cidadãos como atualmente e essa promove outros comportamentos e formas de relacionamento político. Adicionalmente, a tecnologia apresenta novos espaços onde mais facilmente e de forma mais "autocontrolada", o cidadão pode participar civicamente. Genericamente a tecnologia pouco influencia as condições de democracia, contudo suporta capacidades expressivas que promovem narrativas de emancipação, autonomia e liberdade, no imaginário coletivo.

Desde Platão e Aristóteles que os conceitos de público e privado caracterizam a forma como os indivíduos organizam o seu quotidiano e se relacionam com os outros. Estes conceitos são, por isso, determinados histórica e culturalmente. Nos tempos modernos, o privado era concebido como "pessoal" em contraste com o público visto como "impessoal". Consequentemente, o seu entendimento inclui a resposta a questões como: quem beneficia? Quem e como participa? Quem e como governa?

Nas democracias contemporâneas interpenetradas pela tecnologia, os conceitos de público e privado esbatem fronteiras e tornam-se híbridos. Para a autora, verifica-se a privatização do espaço público e o regresso da casa como espaço político. A esfera pública habermasiana, concebida como espaço social que facilita encontros sociais, perde o sentido, pois a discussão política é mantida no "espaço privado digital". As tecnologias 
e a comunicação mediada esbatem limites e promovem a convergência entre o público e o privado e entre o interesse político e a comodificação do quotidiano.

A autora concebe a convergência como reconfiguração e reorganização: (1) tecnológica que modifica a forma como o cidadão se atualiza; (2) de espaços alterando a localização das práticas cívicas; e (3) de práticas sugerindo a continuidade das atividades nas categorias do social, do cultural, do económico e do político. Para Papacharissi, a ação humana atravessa planos privados, públicos e sociais; não necessariamente nesta ordem nem de forma exclusiva, pois a multiplicidade de "espaços" é acompanhada pela multiplicidade de escolhas para o indivíduo. A convergência tecnológica das democracias contemporâneas provoca, desta forma, o esbatimento das diferenças, das distinções que tradicionalmente se podiam fazer ao nível dos media, das audiências, dos públicos, dos cidadãos, dos consumidores e dos produtores. No meio digital, os papéis confundem-se tal como as designações de cidadão, consumidor e produtor. A convergência é, pois, a característica predominante da atual sociedade, expressando a fluidez, a superficialidade, a fragmentação, a interpenetração e a emergência de novos contextos de envolvimento e prática cívica.

Consequentemente, a cidadania em ambientes convergidos evidencia a dificuldade em definir o conceito de cidadania e a necessidade de reconcetualizar o conceito face à evolução das dimensões económicas, socioculturais e políticas, assim como, dos sistemas éticos, morais e religiosos. Para Papacharissi, a cidadania requer envolvimento nos assuntos cívicos e é prescritiva dos modos que os indivíduos seguem para se relacionarem com a esfera política e com a administração pública. Por conseguinte, o conceito tem quatro dimensões básicas: o desenvolvimento democrático; o capitalismo; o consumo e o civismo; e o envolvimento e o capital social. São as alterações nestas dimensões que têm acompanhado a evolução do conceito ao longo da história e que permitem aferir o que é uma "boa cidadania".

Contudo, a autora reconhece que nunca existiu o exercício de uma cidadania perfeita. Traçando a evolução do conceito, detém-se na forma como podemos conceber o conceito nas democracia contemporâneas marcadas pela convergência dos media e por novas práticas cívicas promovidas pelos meios tecnológicos. Assim sendo, diagnostica a existência de cinco modalidades de cidadania:

1. A cidadania do consumidor, que privilegia objetivos materiais, caracterizados pela obtenção de bens, encarando a compra como um compromisso cívico pois permite o estímulo económico e a dinamização dos mercados;

2. A cidadania cultural radicada na cultura enquanto elemento central de afirmação da identidade do indivíduo e dos seus consumos quotidianos, isto é, como definidora do lifestyle e das escolhas do cidadão;

3. A cidadania cosmopolita radicada nos princípios de uma aldeia global na qual os cidadãos se identificam em termos locais, globais e híbridos;

4. A cidadania monitorial que define o cidadão como passivo mas atento, preparado para intervir em momentos de crise que vai antevendo graças à informação que recolhe através dos media. Não obstante, esta atividade é fragmentada e individualizada, desenvolvendo-se na esfera privada e configurando o que Papacharissi chama de "subpolitics" (p. 101). Mas cidadão "monitorizador" não é 
melhor que o cidadão de outras épocas históricas nem mais informado, apesar de ter maior acesso a informação, isto é, maior potencial para a atividade, para o envolvimento.

5. Finalmente, a cidadania digital, que define a responsabilidade cívica através das tecnologias digitais e que, como tal, é desigual face às exclusões de acesso e de literacia.

A estes cinco modelos a autora acrescenta um sexto: a cidadania líquida. Esta categoria faz uma síntese das anteriores apresentando o cidadão do século vinte e um como um indivíduo autónomo e cuja independência pode ser ampliada pelo uso das tecnologias convergentes que permitem maiores oportunidades de interação, autoexpressão, escolhas e controlo. Não obstante estar "digitally equiped, monitorial and voyeuristic, motivated and apathetic, the liquid citizen flows in a fragmented continuum but does not anchor" (p.111).

Apesar do seu potencial democratizador, as tecnologias digitais e convergidas não geram necessariamente capital social e político devido a três fatores: o acesso à informação; a reciprocidade da comunicação e a comercialização do espaço online.

Em primeiro lugar, porque o acesso não conduz ao conhecimento, nem ao envolvimento, nem à confiança, elementos fundamentais para a participação cívica. Por outro lado, existem desigualdades na interpretação da informação, na sua produção e consulta, e facilmente os conteúdos são manipulados por elites e por quem domina a informação offline. Em segundo lugar, a reciprocidade exige igualdade, isto é, que os indivíduos estejam mutuamente envolvidos em conversações. As tecnologias digitais permitem a partilha dos mesmos pontos de vista, mas também o reforço de desigualdades culturais e sociais. Por outro lado, as práticas evidenciam o privilégio na recolha de informação similar e a fraca discussão política em termos de efeitos que a mesma tem na vida e no envolvimento dos indivíduos. Assim sendo, existe predominância de práticas individuais e de interesse privado (do "eu") em detrimento de práticas de promoção do interesse comum. Finalmente, a esfera virtual, ou seja, o espaço criado nas tecnologias digitais, tem-se revelado um espaço de transação de bens e serviços, facilitando trocas comerciais e impulsionando o mercado económico. Consequentemente, revela-se um espaço de exercício e satisfação de interesses privados e não tanto de discussão e impulso da democracia.

Face a estas constatações, a autora defende que a internet é um espaço público a que os indivíduos têm acesso, que podem usar e do qual podem beneficiar, no entanto, não é uma esfera pública, uma vez que está limitada pelos três fatores explicitados anteriormente. Na sua opinião, o espaço virtual simplesmente realça a discussão, enquanto uma esfera virtual enalteceria a democracia (p. 124). Assim sendo, as tecnologias online permitem novos espaços, público e privado, em vez de uma esfera pública. Estes espaços acomodam novos conceitos de público e privado, construídos através da fusão de interesses comuns e individuais.

Esta delimitação conduz a autora à reconceptualização da expressão "esfera privada" que acolhe novos hábitos cívicos que emergem nos espaços híbridos digitais. Para Papacharissi, o cidadão sente que tem mais poder negociando o seu lugar na democracia a partir de uma esfera privada. O deslocar das suas práticas cívicas para esta esfera é 
um ato de dissidência e, por isso, um ato político. O próprio voto deixa de ser um direito do cidadão para passar a ser uma dádiva deste aos partidos políticos e se não existe confiança nestes, o cidadão recusa-se a votar.

A autonomia conferida pelo espaço digital permite-lhe o exercício da cidadania monitorial e líquida a partir de um "território" conhecido onde o indivíduo desenvolve as suas práticas quotidianas e onde decide as suas escolhas, no fundo, que adapta ao seu estilo de vida, ao seu ritmo e à sua vontade. O espaço digital configura, por conseguinte, uma esfera privada contingente, onde o cidadão exerce digitalmente os seus direitos de expressão e reação, onde discute assuntos políticos e participa civicamente. Desta forma, o indivíduo cria o espaço onde contempla, avalia e age; onde está sozinho, mas não isolado, dado que cultiva hábitos cívicos que lhe permitem ligar-se a outros e partilhar prioridades sociais, culturais e políticas. Entre estes hábitos incluem-se: a conectividade remota com outros cidadãos (networked self) aumentando o alcance da esfera privada; o narcisismo digital associado à personalização de conteúdos (weblogs); a sátira e a subversão (pelo uso de plataformas como o Youtube); a agregação de notícias e a pluralidade de filtros de notícias; e o ativismo social. A autora encara estes hábitos como tendências e não como hábitos instalados. Por outro lado, os mesmos demonstram a plasticidade das fronteiras entre o público e o privado através do uso de espaços mediados que promovem uma socialidade privatizada e uma prática de cidadania em rede, mas não envolvida no sentido tradicional do termo.

De forma conclusiva, Papacharissi defende que o conceito de cidadania é adaptável e flexível, assente numa agenda pessoal, prometendo autonomia, mas que não garante privacidade e controlo total. As tecnologias digitais possuem estruturas que promovem a expressão de várias "esferas privadas", garantindo a sua ligação e evitando o isolamento. Não obstante, a esfera privada digital não é apanágio do pessoal nem do político, exigindo uma peculiar mistura de ambos que torna a cidadania menos política em relação à conceção tradicional. Contudo não confere democraticidade, pois é dominada pelo interesse pessoal, muitas vezes instrumentalizado por quem detém a literacia tecnológica e a expertise política. 